\title{
SYNTHESIS OF GEOPOLYMER BASED CLASS-F FLY ASH AGGREGATES AND ITS COMPOSITE PROPERTIES IN CONCRETE
}

\author{
P. GOMATHI ${ }^{1}$, A. SIVAKUMAR ${ }^{2}$
}

\begin{abstract}
This study explores the influence of alkali activators on the initiation of polymerization reaction of alumino-silicate minerals present in class-F fly ash material. Different types of fly ash aggregates were produced with silicate rich binders (bentonite and metakaolin) and the effect of alkali activators on the strength gain properties were analyzed. A comprehensive examination on its physical and mechanical properties of the various artificial fly ash aggregates has been carried out systematically. A pelletizer machine was fabricated in this study to produce aggregate pellets from fly ash. The efficiency and strength of pellets was improved by mixing fly ash with different binder materials such as ground granulated blast furnace slag (GGBS), metakaolin and bentonite. Further, the activation of fly ash binders was done using sodium hydroxide for improving its binding properties. Concrete mixes were designed and prepared with the different fly ash based aggregates containing different ingredients. Hardened concrete specimens after sufficient curing was tested for assessing the mechanical properties of different types concrete mixes. Test results indicated that fly ash -GGBS aggregates (30S2-100) with alkali activator at 10M exhibited highest crushing strength containing of $22.81 \mathrm{MPa}$. Similarly, the concrete mix with $20 \%$ fly ash-GGBS based aggregate reported a highest compressive strength of $31.98 \mathrm{MPa}$. The fly ash based aggregates containing different binders was found to possess adequate engineering properties which can be suggested for moderate construction works.
\end{abstract}

Keywords: Bentonite; Metakaolin; Fly ash; Ground granulated blast furnace slag; Alkali activator; Pelletized aggregates; crushing strength.

\section{INTRODUCTION}

With the rising concern on the shortfall of availability of the conventional building materials like bricks, cement and aggregates it becomes necessary to identify new building materials with the help of advanced technologies. Fly ash is one among the waste which needs a safe disposal as well as to reduce environmental degradation due to its pollution at large scale. The production of artificial light weight coarse aggregate using fly ash has

1 Structural Engineering division, VIT University, Vellore

2 Structural Engineering division, VIT University, Vellore. Corresponding Author email: sivakumara@vit.ac.in 
large potential for utilization in the construction industry and this draws good attention in many parts of the world. The use of lightweight aggregates (LWA) in concrete presents many positive aspects. Harikrishnan, et al., [1] in their studies demonstrated some of the benefits include low-density of concrete achieved by the lightweight aggregates which enables to reduce dead load of the structures, dimensions of columns, slabs and beams. Bijen,; Manikandan, et al., [2,3] stated that the cost of transport and handling equipment for precast elements are also reduced due to use of light weight aggregates. Besides, it was demonstrated that the low heat transfer properties of lightweight aggregate concrete (LWAC) provided higher thermal insulation and had improved the fire resistance. Manikandan, et al.,,; Ramamurthy, et al., [4, 5] investigated extensively the fly ash based light weight aggregates with and without the addition of binders. Their studies showed that the properties of each type of aggregate was found to be different based on the type and amount of binders used. Wang Lijiu, et al.,; Bekir Ilker Topcu, et al., $[6,7]$ in their studies demonstrated that the fly ash based aggregates were the need for the present construction to reduce the dead load of the structure as well to reduce the cost of construction. Verma, et al., [8] investigated that the fly ash waste materials can be converted to aggregates using pelletization processs. Geetha, et al., [9] conducted studies on the formation of fly ash balls in the disc pelletizer with different types of fly ash and binder. It was observed that the efficiency of pelletization was dependent on the fineness of particles, angle of the pelletizer, speed of the drum and duration of pelletization. The physical and mechanical properties of light weight fly ash aggregates were dependent on the type of fly ash either class $\mathrm{C}$ or class $\mathrm{F}$ based on its mineralogical composition. Aggregate properties such as specific gravity, water absorption, bulk density, packing density and gradation greatly influence the grade of concrete produced. In the present study, the influence of adding alkali activators on the mechanical properties was investigated. To assess the basic individual aggregate crushing strength, tests were performed using a CBR testing machine. Mix design was carried out with a particular focus on workability and maximum packing model of aggregates. Further, a systematic analysis was carried out to determine the mechanical properties of concrete mixes prepared with various types of aggregates were studied.

\section{Chemical Activation and Production of Fly ash Aggregates}

The production of lightweight aggregate is followed by granulation technique using the disc type pelletizer machine. A fabricated disc type pelletizer machine was set at an angle of $36^{\circ}$ with a speed of 55 RPM which is kept constant throughout the entire aggregate production. The size of the disc was $0.5 \mathrm{~m}$ diameter with a depth of $0.25 \mathrm{~m}$ as shown in Figure 1. The mix proportions adopted for the various types of lightweight aggregate are given in Table 1. Aggregates production was carried out using cold bonding and further drying of fresh aggregates in natural air drying. Later, the cold bonded aggregates were kept at hot air oven curing temperature $100^{\circ} \mathrm{C}$. strength of cold bonded 
fly ash aggregate (CFA) was improved by using three binder materials such as ground granulated blast furnace slag, bentonite and metakaolin. In the case of fly ash- metakaolin based aggregates, the percentage of binder was optimized at $30 \%$ of the fly ash powder and the water content for production was optimized at $25 \%$. The total duration for a stable aggregate formation (uniform shape) was optimized at 15 minutes duration. Fly ash aggregates were also produced with the addition of 10 molarity of $\mathrm{NaOH}$ containing different percentage of binder. For fly ash -bentonite based aggregates, the percentage of binder used was optimized at $20 \%$ and a mix water content of $25 \%$. Fly ash aggregates without any binders were also produced with the addition of alkali activators $(\mathrm{NaOH}$ solution). The aggregates were produced for 15 minutes duration (as seen in Figure 2).

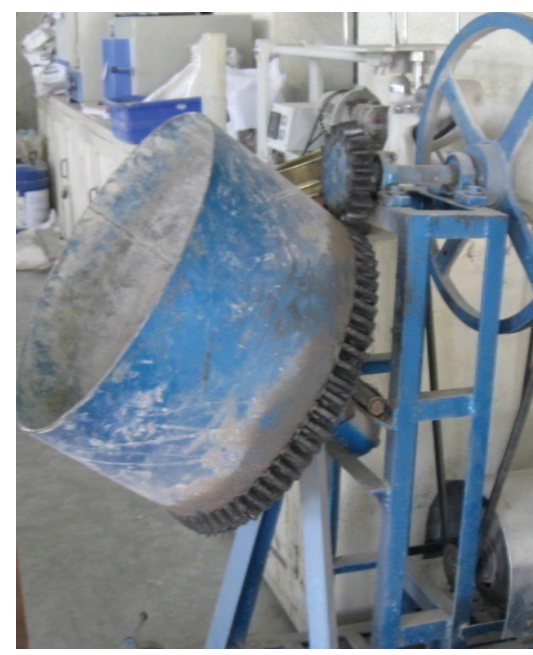

Fig. 1. Disc pelletizer machine

Table 1

Mix proportions of various binder materials for manufacturing fly ash aggregates

\begin{tabular}{|c|c|c|c|c|c|c|}
\hline Aggregate mix Id & $\begin{array}{c}\text { Fly ash } \\
(\mathrm{gms})\end{array}$ & $\begin{array}{c}\text { Bentonite } \\
(\mathrm{gms})\end{array}$ & $\begin{array}{c}\text { Metakaolin } \\
\text { (gms) }\end{array}$ & $\begin{array}{c}\text { Granulated blast } \\
\text { Furnace slag } \\
(\mathrm{gms})\end{array}$ & $\begin{array}{c}\text { Sodium } \\
\text { hydroxide } \\
\text { (gms) }\end{array}$ & $\begin{array}{c}\text { Water } \\
\text { content } \\
\text { (gms })\end{array}$ \\
\hline FL3-100 & 1000 & - & - & - & 100 & 250 \\
\hline 20BT2-100 & 800 & 200 & - & - & 100 & 250 \\
\hline 30MT3-100 & 700 & - & 300 & - & 120 & 250 \\
\hline 30S2-100 & 700 & - & - & 300 & 100 & 250 \\
\hline
\end{tabular}




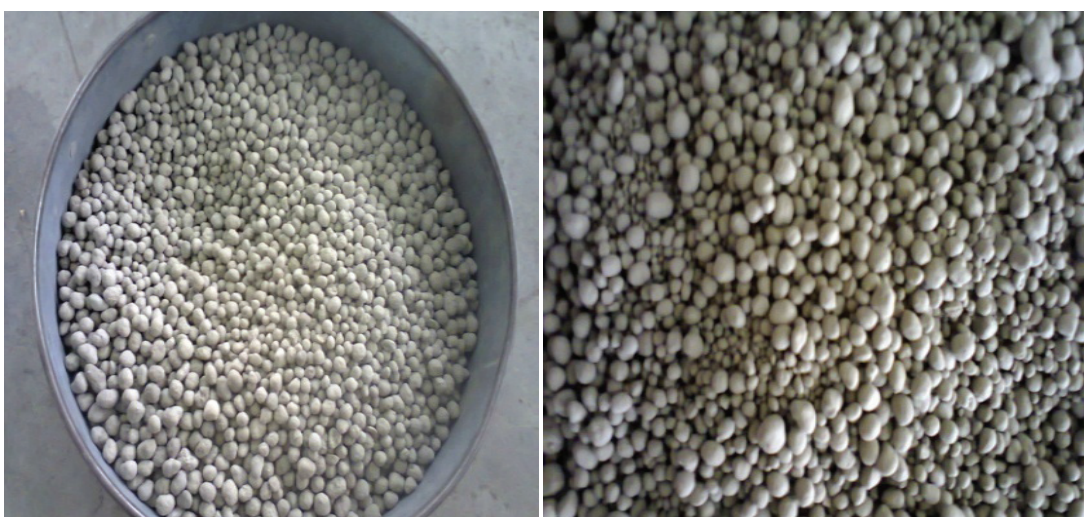

Fig. 2. Fly ash lightweight aggregate

\section{Characterization Tests on Fly ash Aggregates}

\subsection{SPECIFIC GRAVITY}

The specific gravity of the various fly ash aggregates produced was determined by calculating the weight of the aggregates in air divided by the weight of an equal volume of water. This quantity was used in the mixture proportion calculations to find the absolute volume of aggregates that fills the given volume of concrete mixture. The absolute volume of an aggregate defines the space occupied by the aggregate alone i.e. volume of solid matter and internal aggregate pores, excluding the voids between particles. The physical and mechanical properties of various types of lightweight aggregate produced are given in Table 2.

Table 2

Physical and Mechanical properties of fly ash lightweight aggregate

\begin{tabular}{|c|c|c|c|c|c|c|}
\hline \multirow{3}{*}{$\begin{array}{l}\text { Aggregate } \\
\text { mix Id }\end{array}$} & \multicolumn{5}{|c|}{ Physical properties } & \multirow{3}{*}{$\begin{array}{c}\begin{array}{c}\text { Mechanical } \\
\text { properties }\end{array} \\
\text { Impact value }(\%)\end{array}$} \\
\hline & \multicolumn{2}{|c|}{ Specific gravity } & \multicolumn{2}{|c|}{ Bulk density $\left(\mathrm{Kg} / \mathrm{m}^{3}\right)$} & \multirow{2}{*}{$\begin{array}{c}24 \text { hrs Water } \\
\text { absorption (\%) }\end{array}$} & \\
\hline & SSD & OD & LBD & RBD & & \\
\hline FL3-100 & 1.89 & 1.55 & 978.34 & 1052.23 & 21.26 & 50.47 \\
\hline 20BT2-100 & 1.85 & 1.62 & 949.68 & 1003.88 & 16.39 & 35.00 \\
\hline 30MT3-100 & 1.80 & 1.53 & 848.41 & 987.89 & 17.86 & 38.00 \\
\hline 30 S2-100 & 1.68 & 1.56 & 983.44 & 1001.56 & 13.01 & 31.96 \\
\hline
\end{tabular}

Notes: SSD-Saturated surface dry condition, OD-Oven dry condition, LBD-Loose bulk density, RBD-Rodded bulk density 


\subsection{Gradation}

Grading refers to the distribution of particle sizes present in the whole mass and was determined using a standard set of sieves.

\subsection{BULK DENSITY}

The bulk density of an aggregate was determined from the mass of the aggregate divided by the volume of particles and the void spaces between the particles.

\subsection{WATER ABSORPTION}

In addition to the mix water required for concreting, the water required for initial aggregate wetting was determined using water absorption. Absorption (\%) was computed by subtracting the oven dry mass from the saturated surface-dry mass and by dividing the oven-dry mass.

\subsection{Aggregate Crushing strength}

The individual aggregate crushing strength test was performed using a CBR testing machine shown in Figure 3. The crushing strength of the individual pellets was determined using the formula [10].

$$
\sigma=\frac{2.8 P}{\pi X^{2}}
$$

Where $\sigma=$ individual crushing strength $\left(\mathrm{N} / \mathrm{mm}^{2}\right) ; \mathrm{P}=$ failure load $(\mathrm{N}) ; \mathrm{X}=$ distance between the loading point, i.e. diameter of aggregates

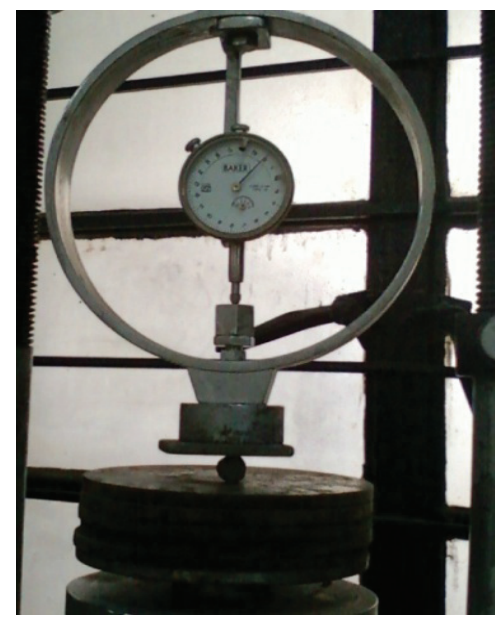

Fig. 3. CBR testing machine 


\subsection{Aggregate impact strength}

Aggregate impact strength was conducted (as shown in Figure 4) to determine the toughness of various types of aggregates as per the standard procedure. The aggregate impact value was determined to conform whether it is less than $30 \%$ and $45 \%$ to be used in road construction or to be used in building construction respectively.

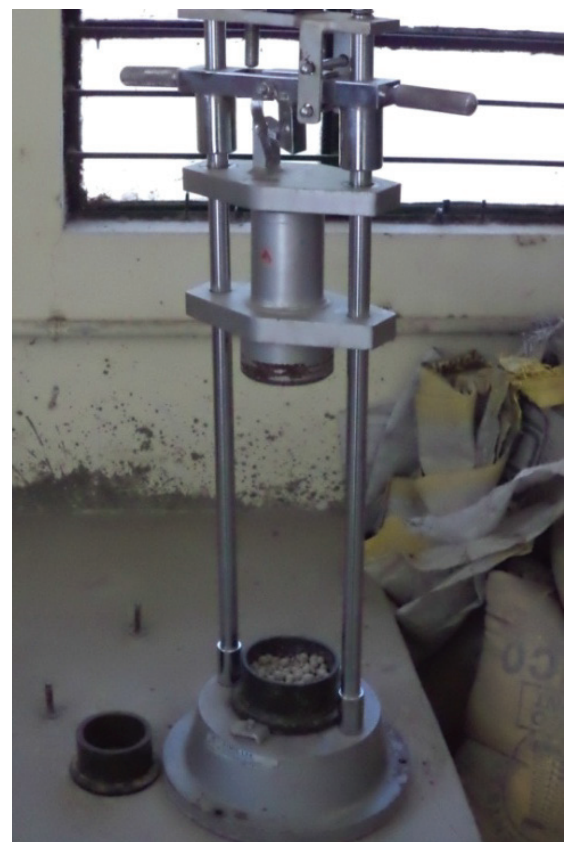

Fig. 4. Impact testing machine

\section{Light Weight Concrete Mix Design Procedure}

Mix design was arrived based on the principle of maximum packing model as shown in Figure 5. The maximum packing model for each type of aggregate is determined. For obtaining the maximum packing model, initially the aggregates were filled in a cylindrical container of known volume and the amount of water required to fill the container is calculated. This volume of water required to fill the aggregates will be equal to the volume of the voids present in the cylinder. Later by assuming the volume of voids which is equal to the volume of the mortar required to fill the mortar; the percentage of coarse aggregate and mortar for the concrete mix was calculated. However, during concreting it was found that the mix with maximum packing model proportion showed poor workability due to aggregate friction. The detailed mix proportions of various packing models arrived is provided in Table 3. 
商

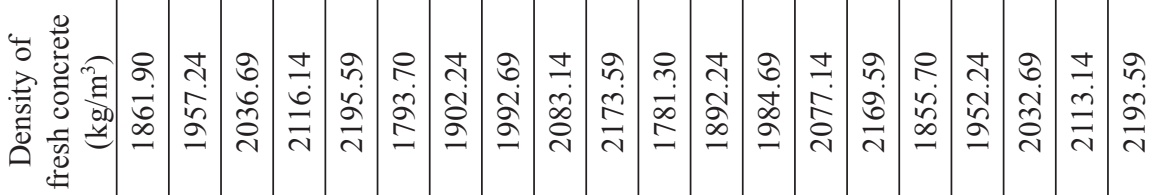
言吉

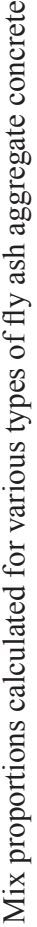

\begin{tabular}{|c|c|c|c|c|c|c|c|c|c|c|c|c|c|c|c|c|c|c|c|c|}
\hline के & $\because$ & n & $\because$ & n? & $n$ & ? & $\because$ & $\because$ & $\stackrel{n}{\sim}$ & $\stackrel{n}{-}$ & $\cong$ & $\cong$ & $\stackrel{n}{-}$ & $\cong$ & $\stackrel{n}{-}$ & $\stackrel{n}{-}$ & ? & $\cong$ & "n & ' \\
\hline$\Sigma$ & & & 0 & & $\infty$ & & $n$ & & & & & $n$ & 0 & & $\triangleright$ & n & $n$ & 0 & P & \\
\hline
\end{tabular}

J

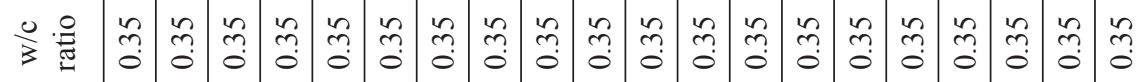

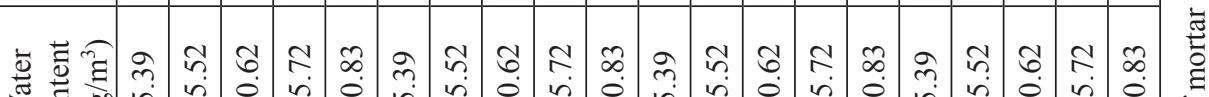
尝 苛

¿.

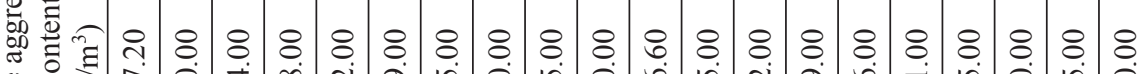
莺

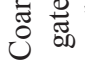

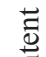

矛 若

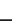
苞 苞节

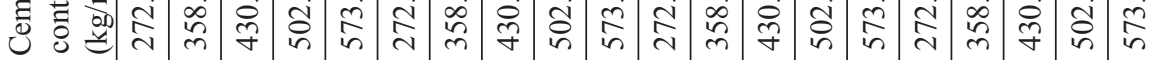

4

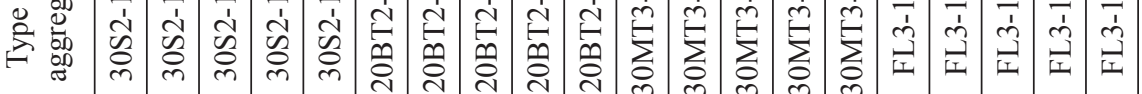

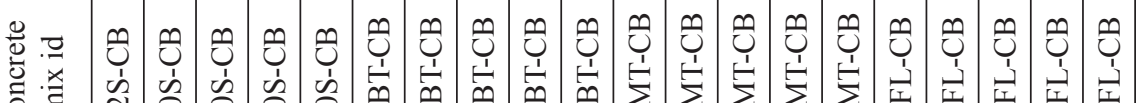

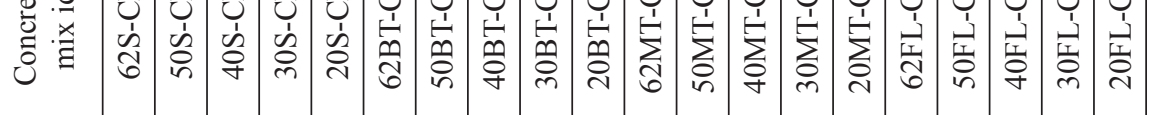




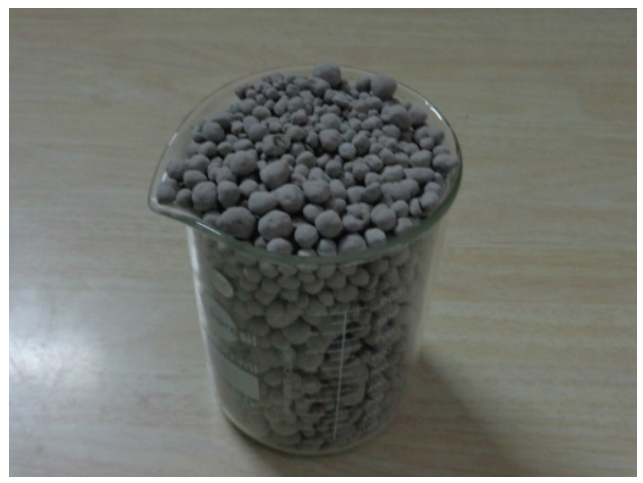

Fig. 5. Maximum packing model

\subsection{Characterization Tests of Concrete}

The compressive strength and split tensile strength tests were conducted for determining the mechanical properties of various light weight aggregate concrete produced. The durability properties of the concrete were also determined using water absorption test for various concrete mixes.

\subsection{Compressive STRENGTH}

Compression and split tension tests were conducted in a $2000 \mathrm{kN}$ capacity testing machine (shown in Figure 6). Cube moulds of size $100 \times 100 \times 100 \mathrm{~mm}$ were used for testing fresh concrete specimens and the load at failure divided by the area of specimen was used for calculating the stress.

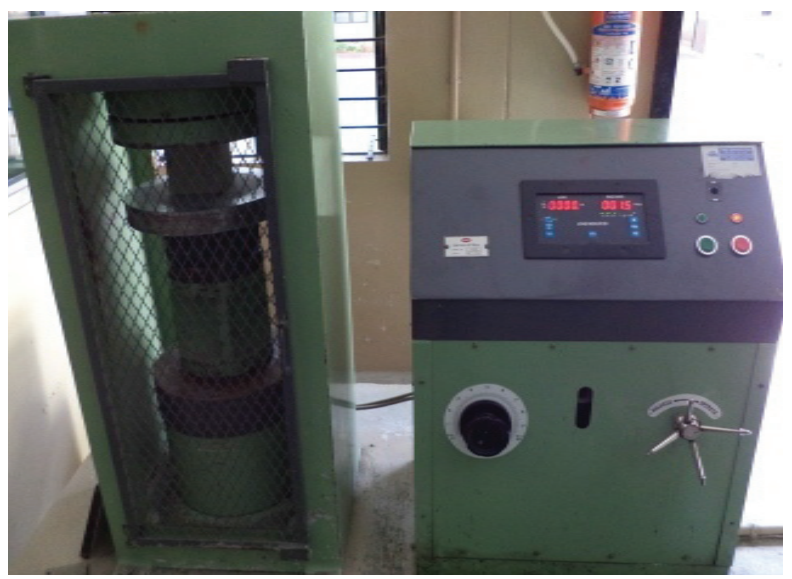

Fig. 6. Compression testing machine 


\subsection{Split tensile Strength}

Split tensile tests were carried on standard cylinders of size $100 \times 200 \mathrm{~mm}$. The test consists of applying a compressive line load along the opposite generators of a concrete cylinder placed with its axis horizontal between the compressive platen. The magnitude of this tensile stress is given by the formula $(2 \mathrm{P} / \pi \mathrm{dl})$ (as seen in Figure 7 ).

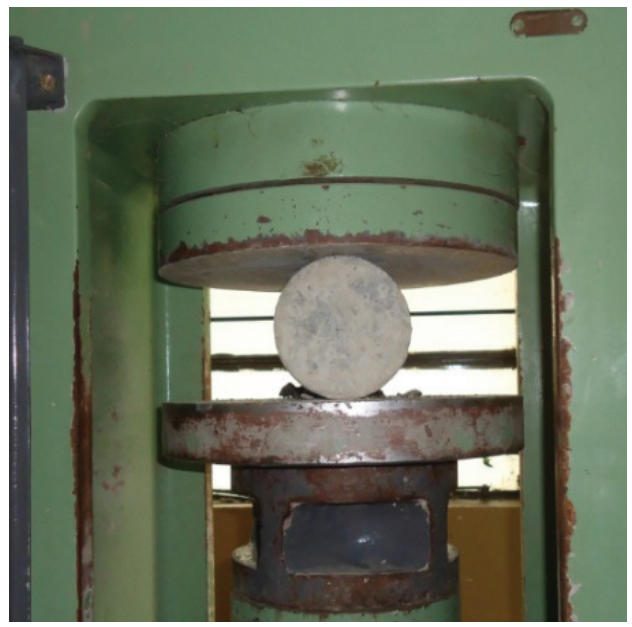

Fig. 7. Split tensile testing set up

\section{Experimental Test Results and Discussions}

\subsection{Properties of Aggregate}

The physical properties of aggregates were studied and all the aggregates were having a density range from 848.41 to $1052.23 \mathrm{~kg} / \mathrm{m}^{3}$. It can be noted from Table 2 that, fly ash-metakaolin aggregates (30MT3-100) showed the lowest bulk density value. It can be also noted from the gradation curve provided in Figure 8 that, all the fly ash based aggregates were found to have uniform gradation and possess all the intermediate size ranges as that of conventional aggregates. Similarly, it was found that fly ash-GGBS aggregates were having lesser water absorption compared to all other aggregates (as seen in Figure 9). Among all the aggregate types, GGBS based fly ash aggregates showed the lowest water absorption. In the case of metakaolin aggregates, the mix with fly ash and sodium hydroxide showed the lowest water absorption. Crushing strength of individual aggregates containing different binders are given in Figures 10 and 11 . A maximum crushing strength of around $22.81 \mathrm{MPa}$ was noted for fly ash-GGBS aggregate (as seen in Figure 10). Also, fly ash-GGBS aggregates (12mm diameter) kept at $100^{\circ} \mathrm{C}$ showed the highest crushing strength value of $18.85 \mathrm{MPa}$ and fly ash-metakaolin 
aggregates showed a highest strength value of $10.03 \mathrm{MPa}$ as evident in Figure 10. It can be also noted from the test results that, metakolin aggregates showed highest crushing strength compared to bentonite aggregates. In the case of cold bonded aggregates, it was noted that the sufficient curing after initial drying in hot air oven provides adequate strength enhancement. The results also confirm that, within the standard limits, the pelletized aggregates can be used for construction purposes. It can be drawn from the test results that the fly ash cold bonded aggregates had shown improved engineering properties with the addition of binders. A good improvement on the physical and mechanical properties was noticed with the adequate hot curing technique at $100^{\circ} \mathrm{C}$. The strength of aggregates was found to be influenced by the initial accelerated curing in hot air oven with a result of micro-structural densification. In the case of bentonite and metakolin based aggregates the reactive silica was influential with the chemical activators added. This addition of alkali hydroxide attributed to the rapid geopolymeric reaction of silica and alumina present in the source material. Among the different aggregates tested the fly ash-GGBS aggregates showed good engineering properties as well as satisfied the standard requirement to be used as a construction material.

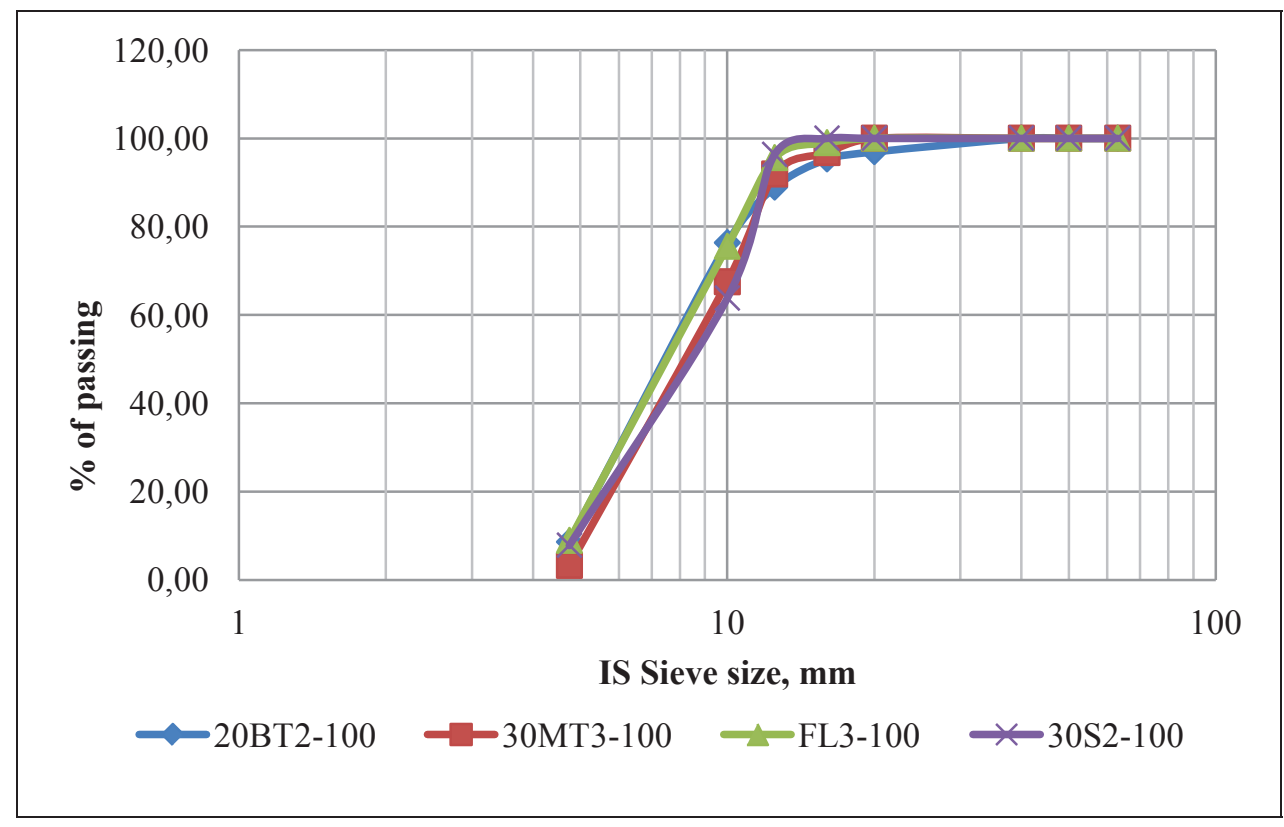

Fig. 8. Gradation of various types of aggregates 


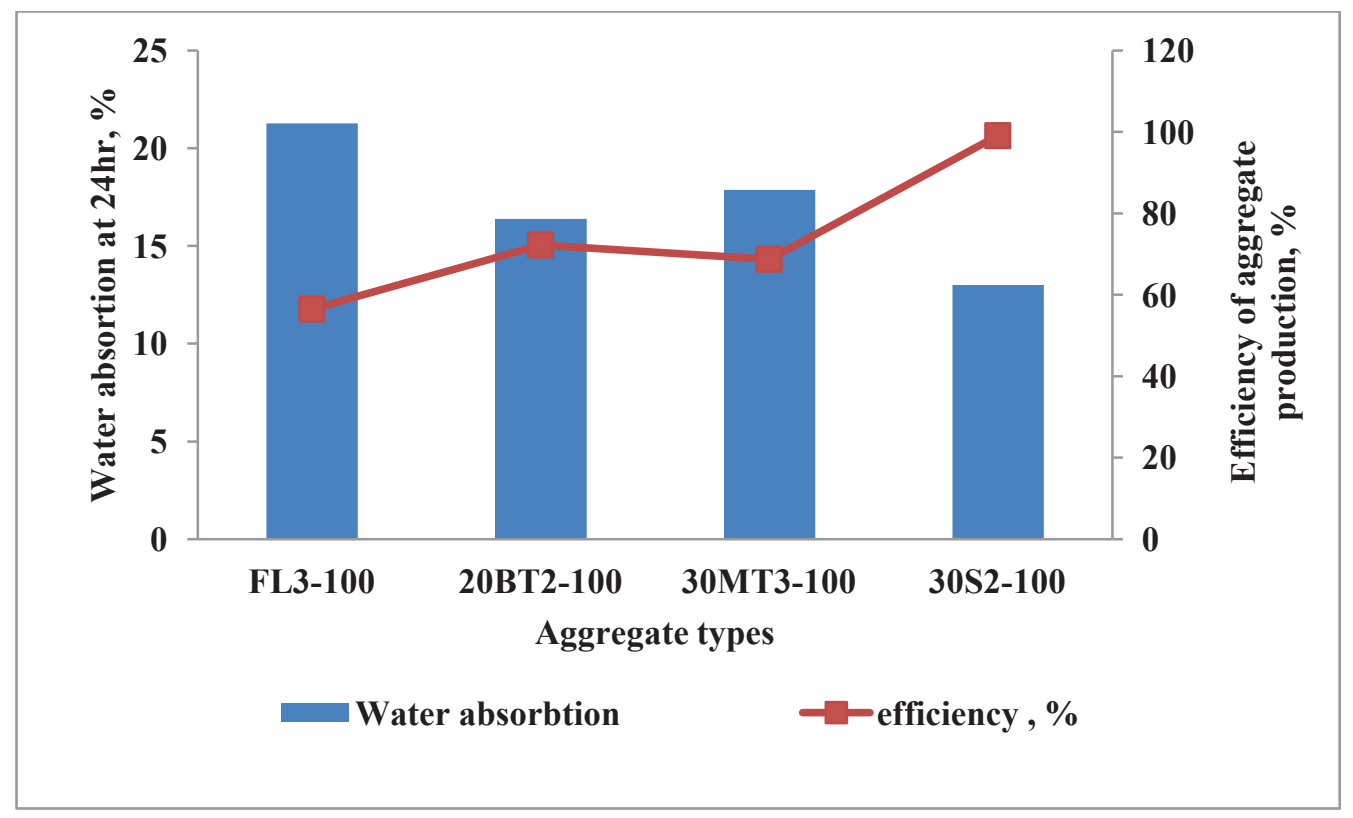

Fig. 9. Production efficiency and Water absorption of various type of aggregates

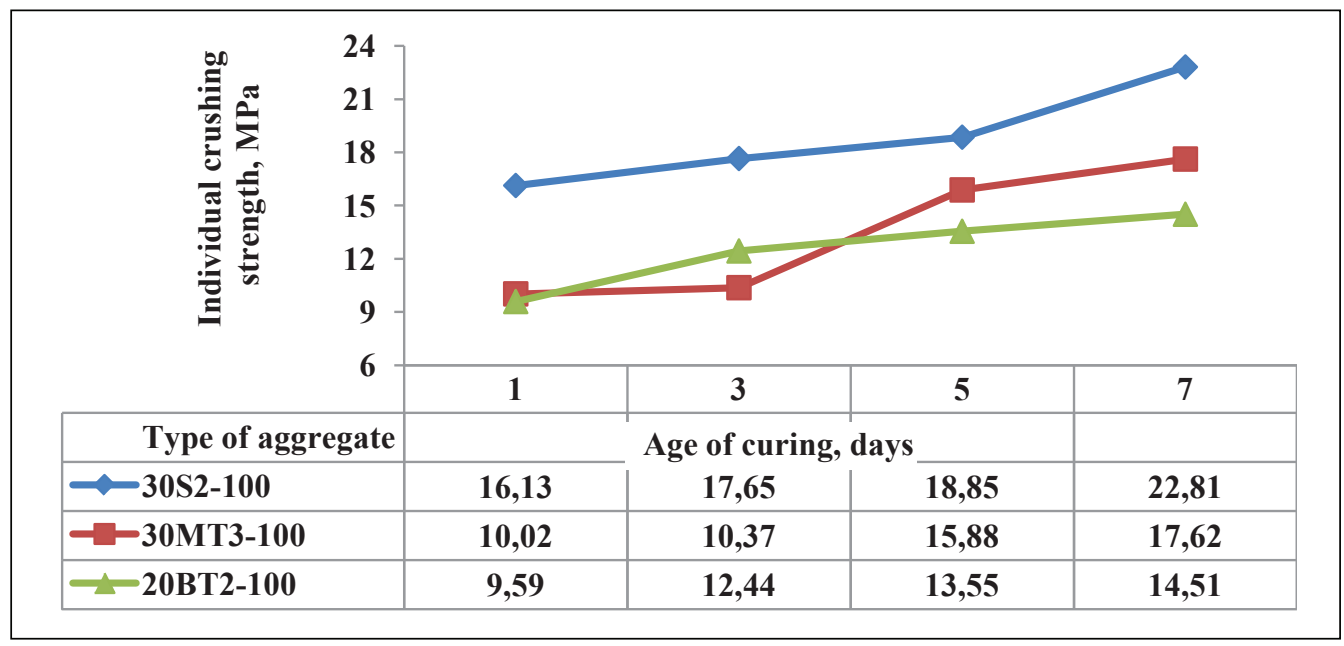

Fig. 10. Crushing strength of various types of fly ash aggregate at oven curing $100^{\circ} \mathrm{C}(10 \mathrm{~mm}$ diameter of pellet 


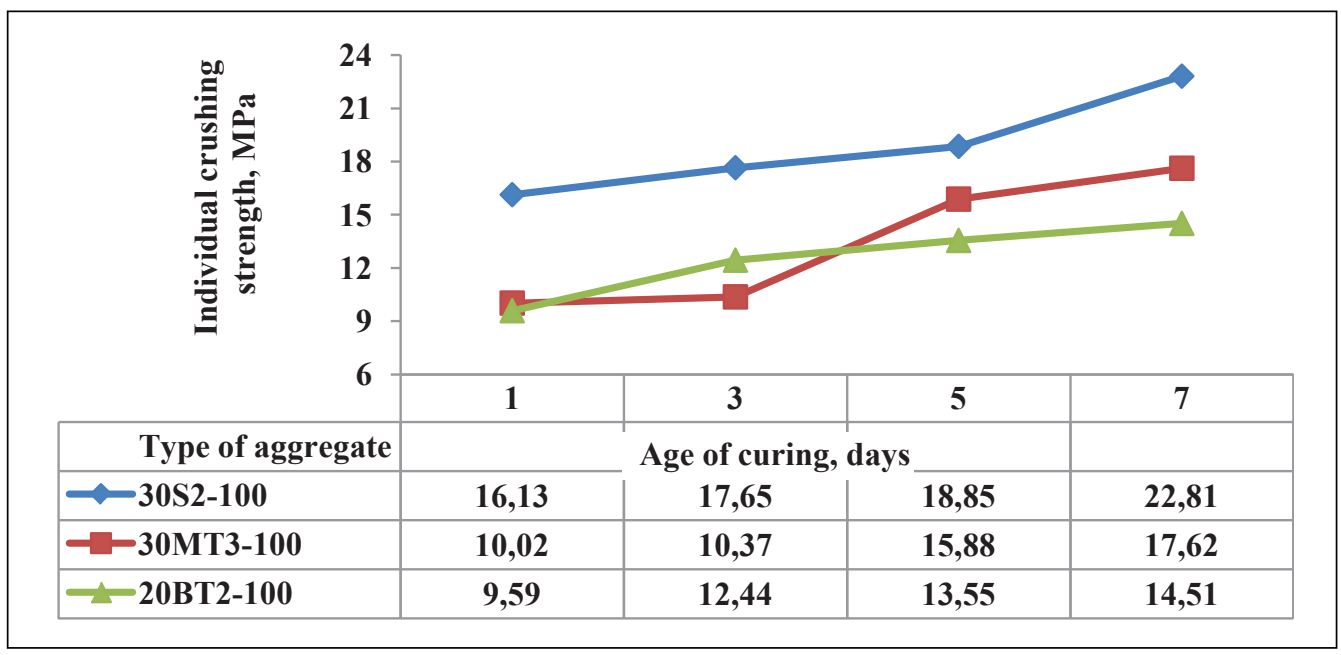

Fig. 11. Crushing strength of different types of fly ash aggregate at oven curing $100^{\circ} \mathrm{C}(12 \mathrm{~mm}$ diameter of pellets)

The experimental trends given in Figure 12 represents the test results on the alternate wetting and drying cycle for the various types of fly ash based aggregates. The maximum percentage of weight loss was observed to be around $1.41 \%$ for fly ash-metakaolin aggregate and $1.32 \%$ for fly ash-GGBS aggregate. The crushing strength of fly

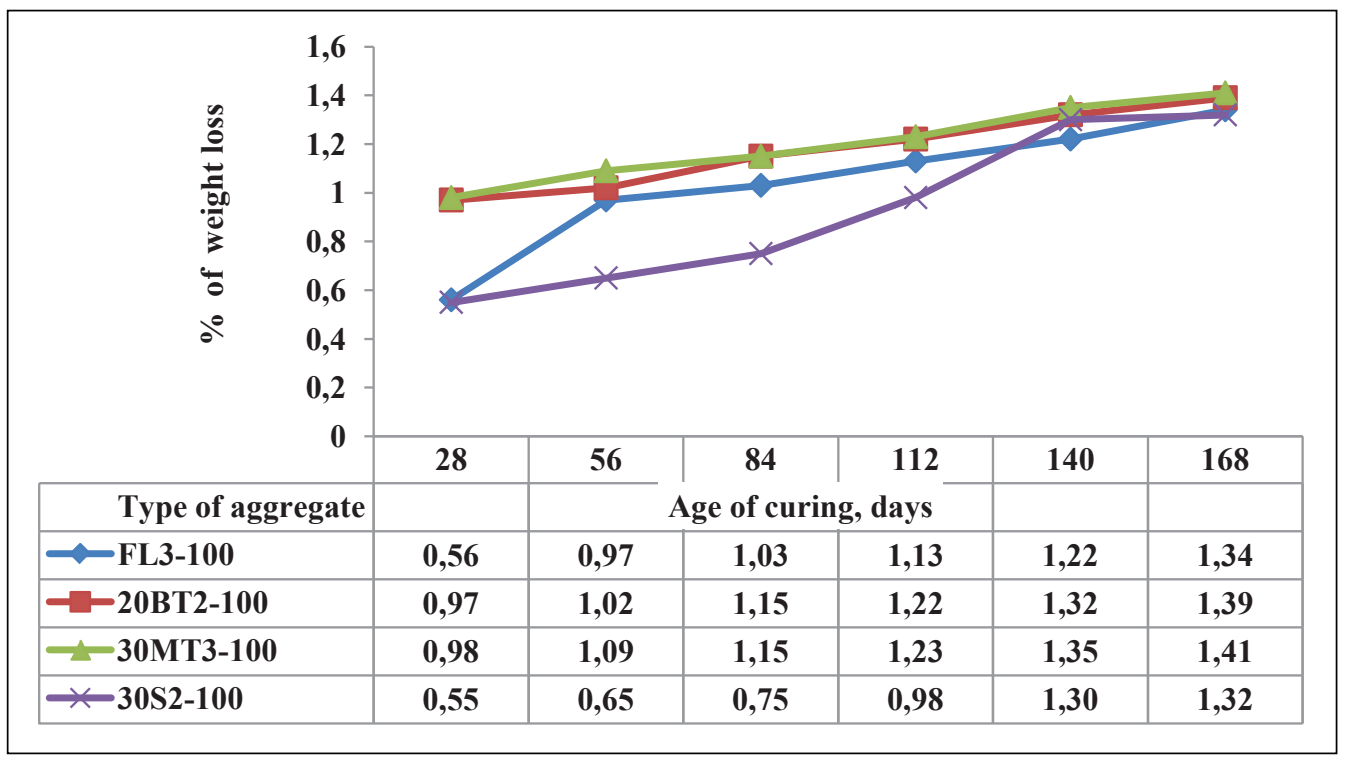

Fig. 12. Alternate wetting and drying process of light weight aggregate at different days of curing 
ash aggregate ( $10 \mathrm{~mm}$ diameter of pellet) were tested after alternate wetting and drying cycles up to 168 days and the test results are shown in Figure 13. The minimum percentage of strength loss for fly ash-GGBS aggregate was found to be $2.17 \%$ (at 168 th cycle) compared to the 84 days crushing strength.

\begin{tabular}{|ll|l}
\hline \multicolumn{2}{|c|}{30} \\
\hline
\end{tabular}

Fig. 13. Crushing strength of aggregates cured in alternate wetting and drying environment $(10 \mathrm{~mm}$ diameter of pellets)

\subsection{Mechanical Properties of LWAC}

The mechanical crushing strength properties of various concrete mixes incorporating different aggregate types are presented in Table 4. It can be drawn from the test results that, the compressive properties of concrete mixes were greatly affected with the packing volume of aggregates. As seen from Figures 14 and 15 that, the compressive strength of concrete mixes was found to decrease with the increase in packing volume of aggregates. This decrease in strength essentially occurs due to light weight of aggregates occupying large volume of the concrete. However, the decrease in aggregate fraction had resulted in higher compressive strength. It was observed that the mix containing $40 \%$ bentonite aggregates with $60 \%$ mortar composition showed better workability and exhibited a highest compressive strength compared to maximum packing of coarse aggregate concrete mixes. The influence of high temperature oven curing at $100^{\circ} \mathrm{C}$ was comparatively higher than the normal water cured concrete specimens. Whereas, in the case of fly ash aggregates alone the addition of $40 \%$ coarse aggregate 
旁

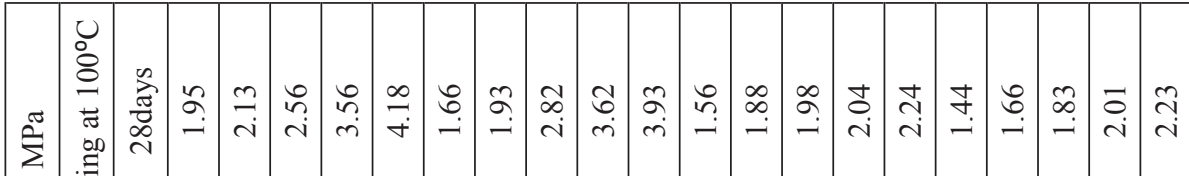

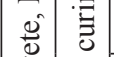

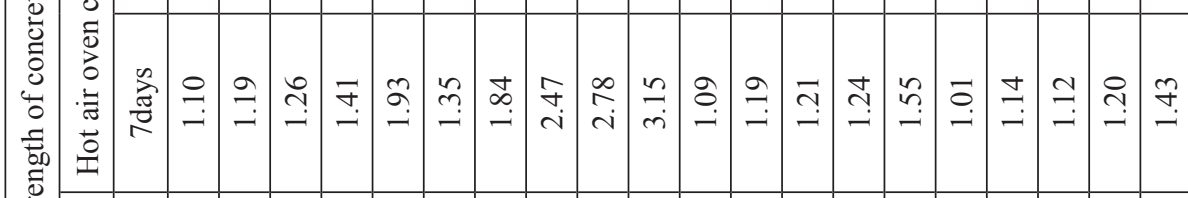

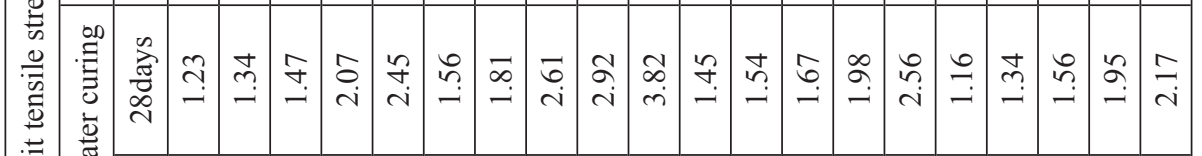

$$
\begin{aligned}
& \text { की }
\end{aligned}
$$

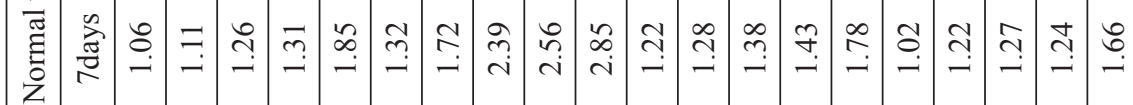

ป

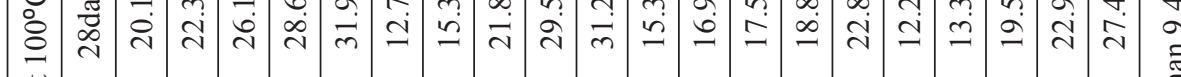
त)

浔

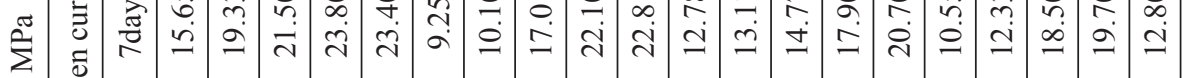

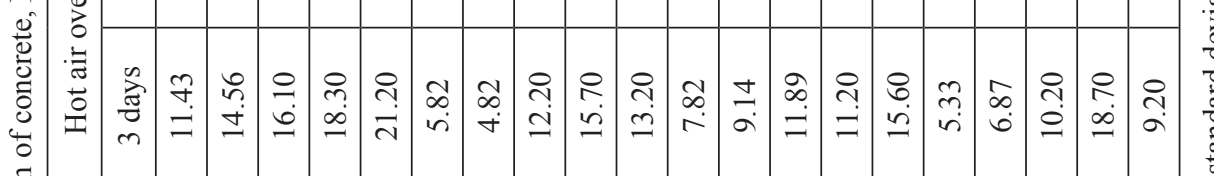

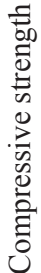

离 $\infty$ กิ

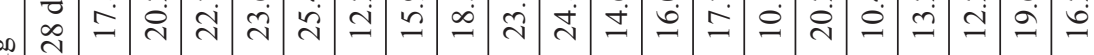

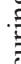

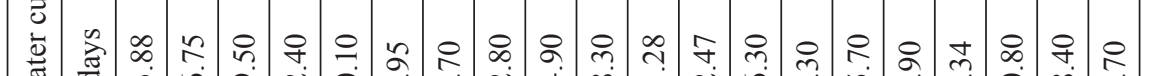

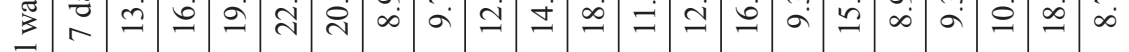
范

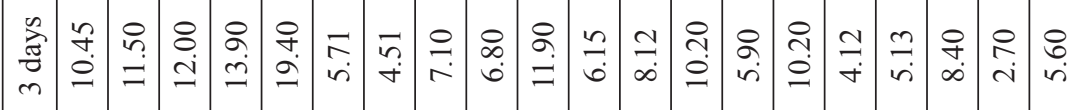

.그

$\stackrel{. 凶}{*}$ 䆓 $\frac{0}{0}$

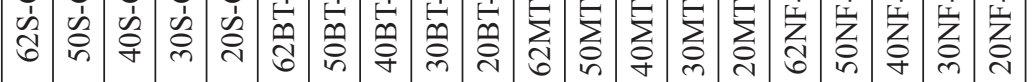




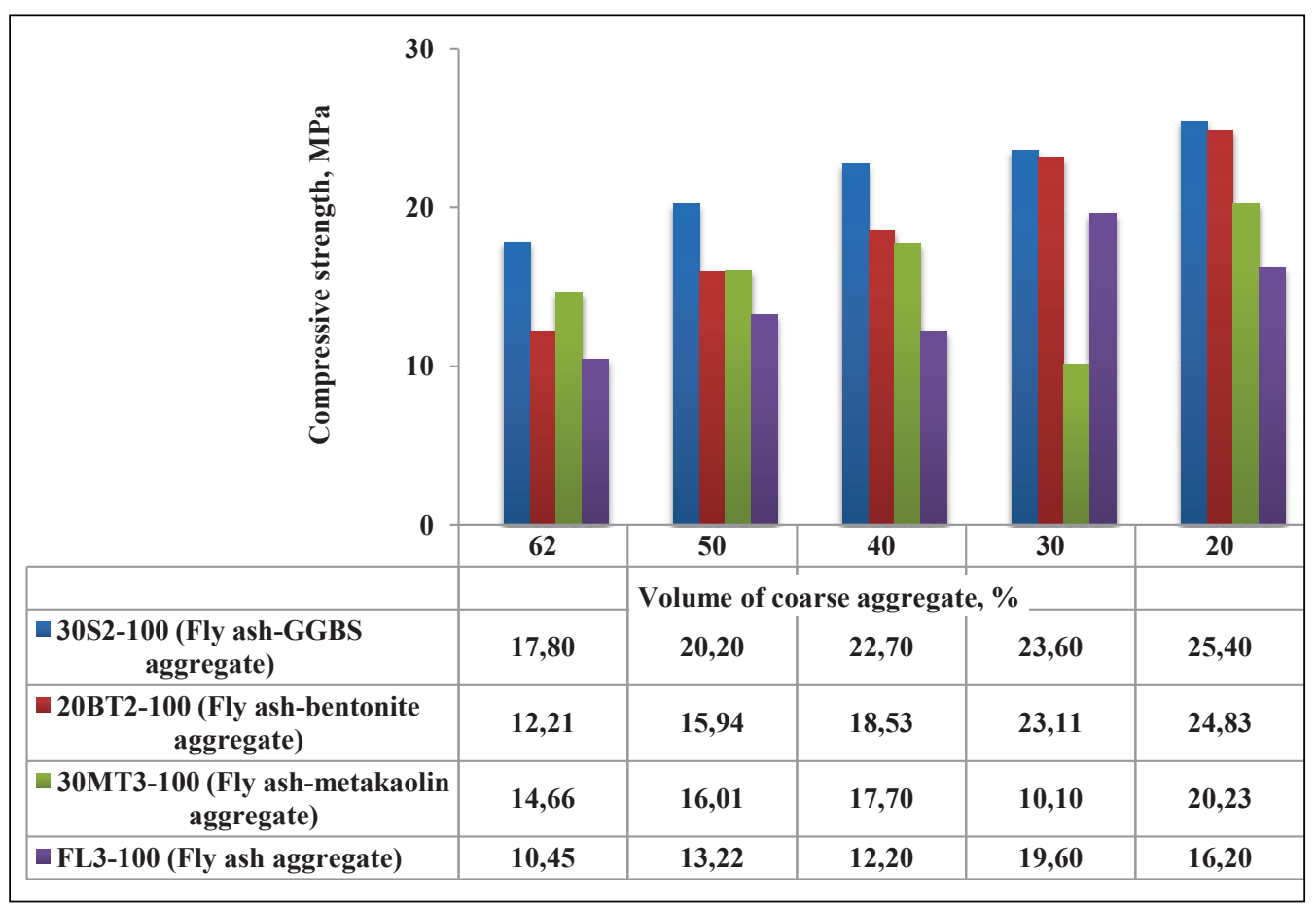

Fig. 14. Compressive strength of different types of fly ash aggregate concrete cured in water upto 28 days

and $60 \%$ mortar mix exhibited a higher compressive strength compared to maximum packing coarse aggregate concrete mixes at water curing and oven curing. Further it can be seen from Figures 14 and 15 that the effect of curing plays an important role on the strength development of concrete mixes. In the case of water cured specimens a maximum strength reported was around $25.4 \mathrm{MPa}(20 \mathrm{~S}-\mathrm{CB})$. However, the effect of high temperature oven curing has accelerated the geo-polymerisation of concrete and the concrete mix containing bentonite concrete mixes reported a highest compressive strength (31.22 MPa). For all the concrete mixes the specimens kept at oven curing had shown a significant increase in the compressive strength. This could possibly due to accelerated polymerisation at higher temperature wherein the reaction with silica and alumina provides aluminosilicates. This chain reaction can be favourable only at heat curing rather at ambient temperature.

Compared to the compressive strength values the experimental trends mixes observed for split tensile strength values were also found to be similar. Fly ash aggregates with $40 \%$ coarse aggregates and $60 \%$ mortar showed the highest split tensile values compared to maximum packing of coarse aggregate concrete mixes. The split tensile strength values of various fly ash based concrete mixes are shown in Figures 16 and 17 cured in water and hot air oven respectively. It can be noted that the split tensile strength 


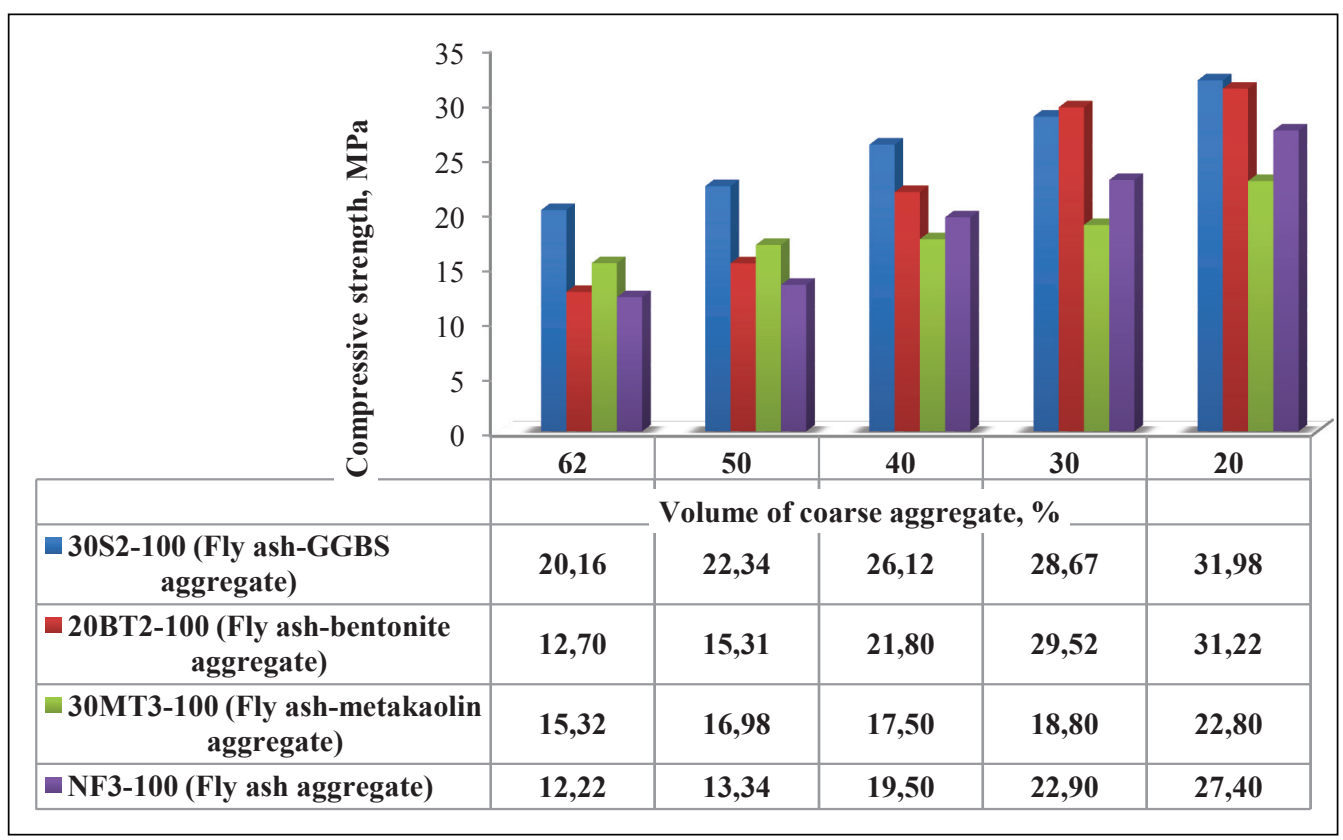

Fig. 15. Compressive strength of different types of fly ash aggregate concrete in Hot air oven curing at $100^{\circ} \mathrm{C}$ (28 days strength)

of bentonite mixes containing 20BT-CB mix i.e. $20 \%$ coarse aggregate and $80 \%$ mortar mix showed higher split tensile strength value of $3.82 \mathrm{MPa}$. In the case of metakaolin concrete mixes (20MT-CB) containing 20\% coarse aggregate and $80 \%$ mortar composition subjected to oven curing were showing higher split tensile strength value of 2.56 MPa. The experimental trends shown in Figure 17 showed that the split tensile strength value of 20FL-CB mix subjected to oven curing was around $2.23 \mathrm{MPa}$. It is noted clearly that the concrete specimens kept in oven curing were having higher split tensile strength values compared to normal water curing. However, the split tensile strength values of activated fly ash aggregates (20FL-CB mix) subjected to oven curing and water curing showed higher split tensile strength values. In the case of durability properties of the aggregates the continuous wetting and drying was used to calculate the percentage of water absorbed by the various concrete mixes. The test results shown in Figures 18 to 21 exhibits the flexural strength of various types of concrete mixes tested at 7 days and 28 days. A maximum bending strength of $4.33 \mathrm{MPa}$ was obtained in the case of LWAC concrete specimens $(20 \mathrm{~S}-\mathrm{CB})$ subjected to hot air oven curing at $100^{\circ} \mathrm{C}$ (as seen in Figure 19). The flexural bending properties were noticeably improved in the case of LWAC concrete mixes consisting of fly ash aggregates binders. Also, the effect of accelerated curing of concrete specimens had shown significant increase on the overall strength improvement compared to the normal water cured specimens. 


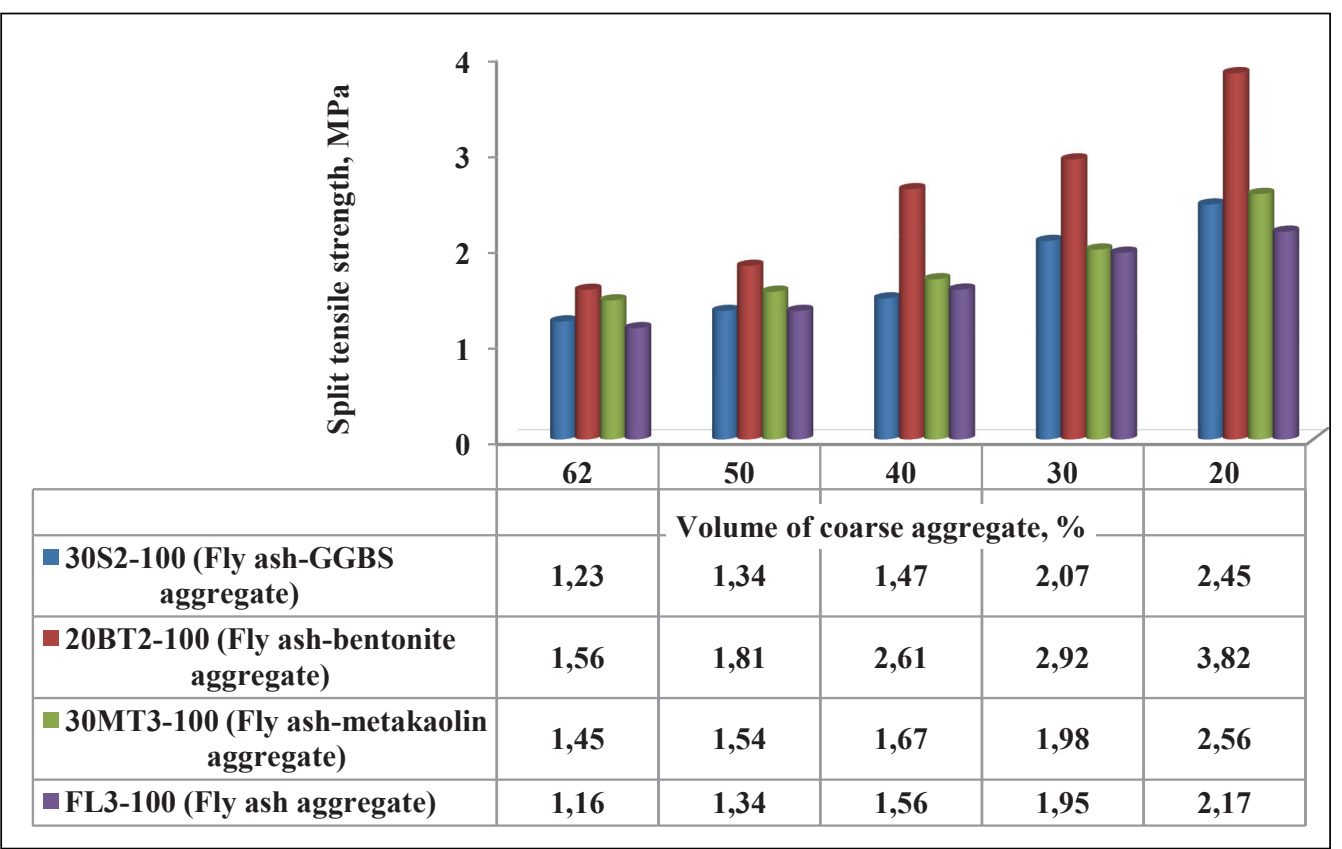

Fig. 16. Split tensile strength of LWAC in water curing (28 days strength)

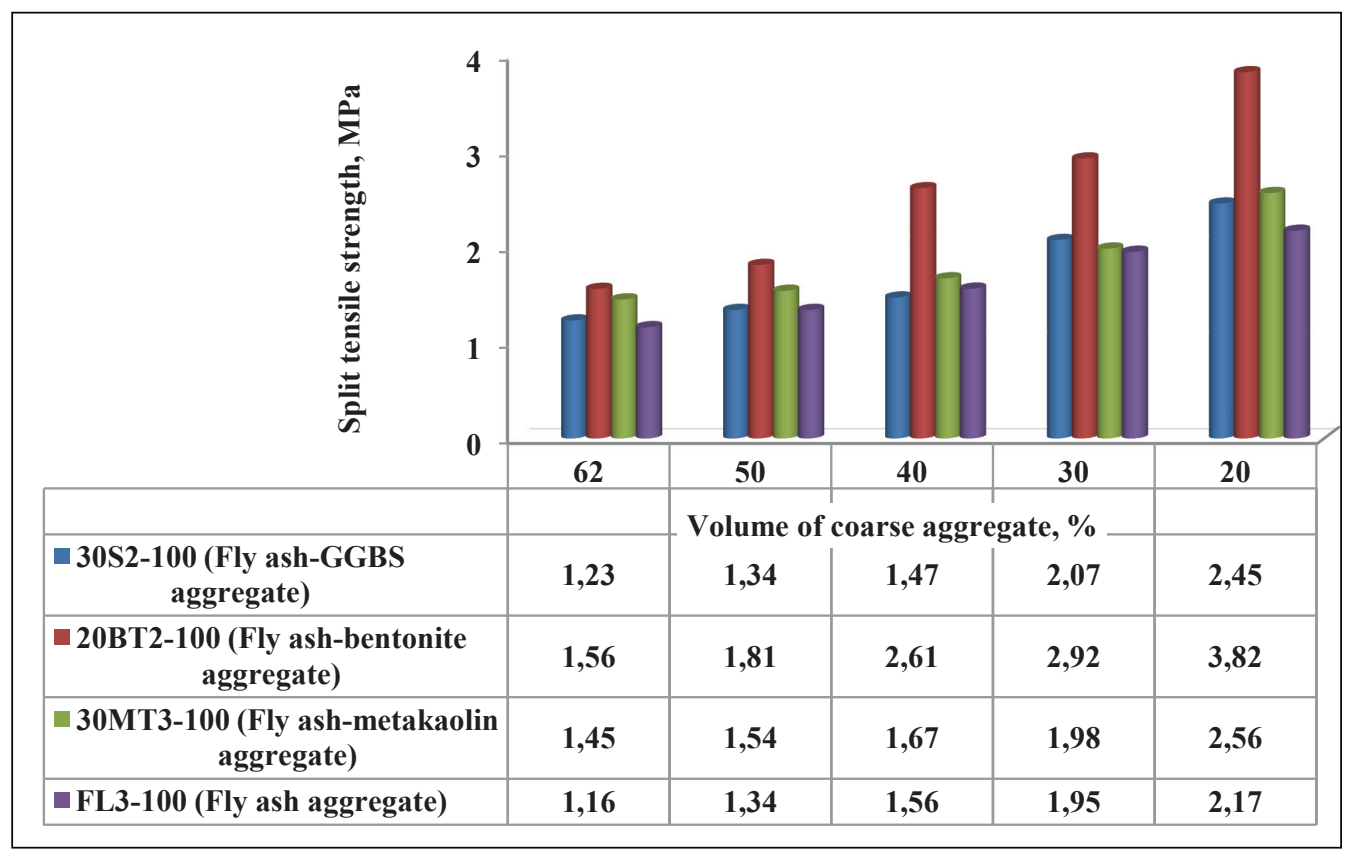

Fig. 17. Split tensile strength of LWAC in hot air oven curing at $100^{\circ} \mathrm{C}$ ( 28 days strength) 


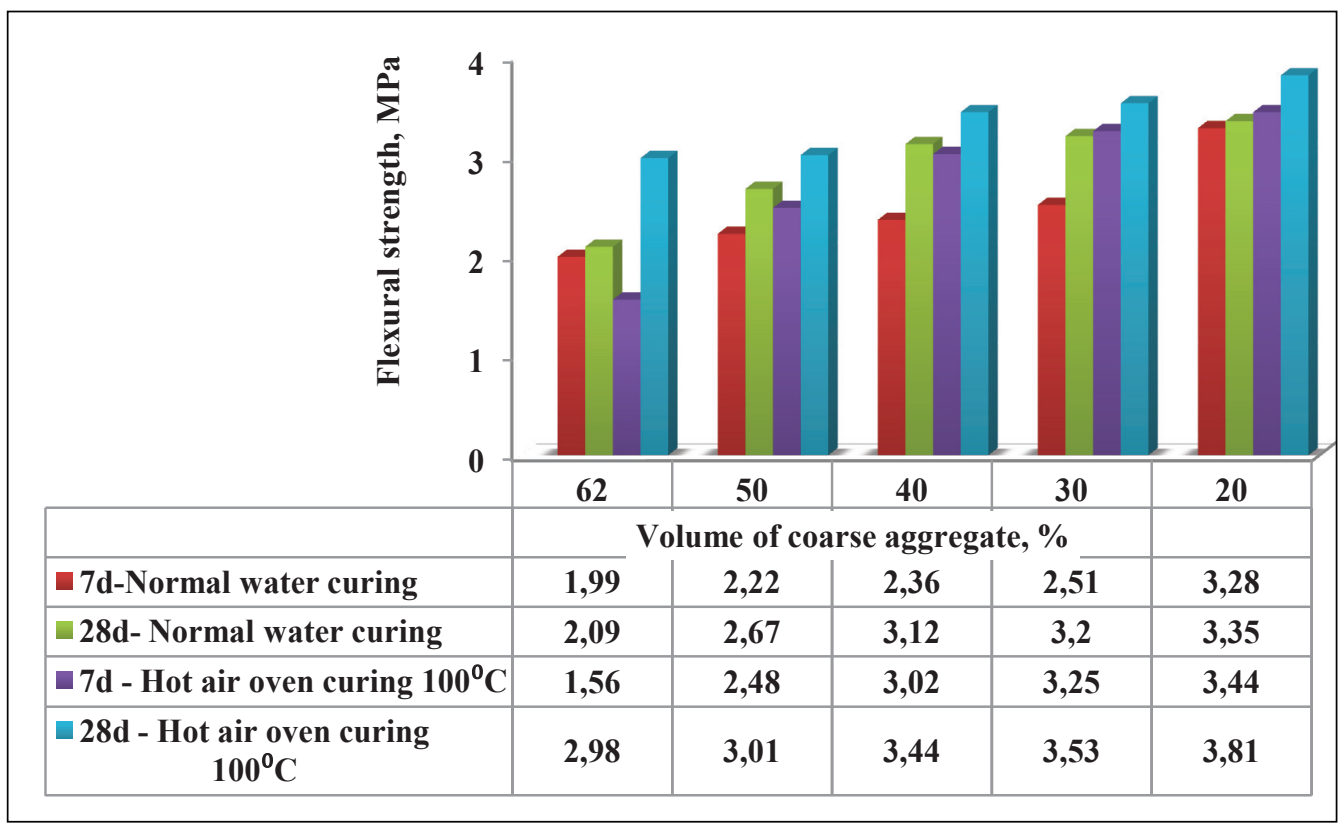

Fig. 18. Flexural strength of fly ash aggregate concrete in water curing and hot air oven curing

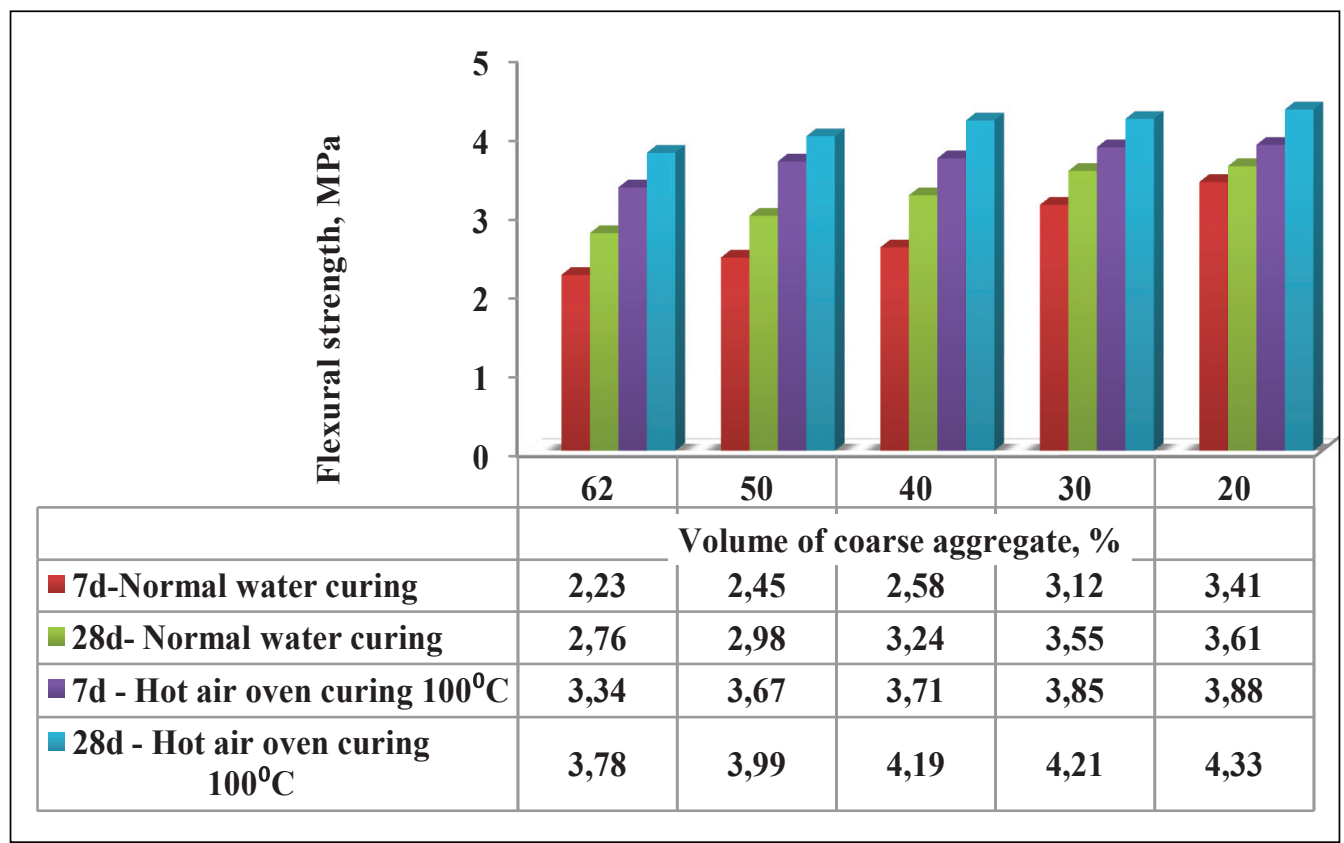

Fig. 19. Flexural strength of fly ash-GGBS aggregate concrete in water curing and hot air oven curing 


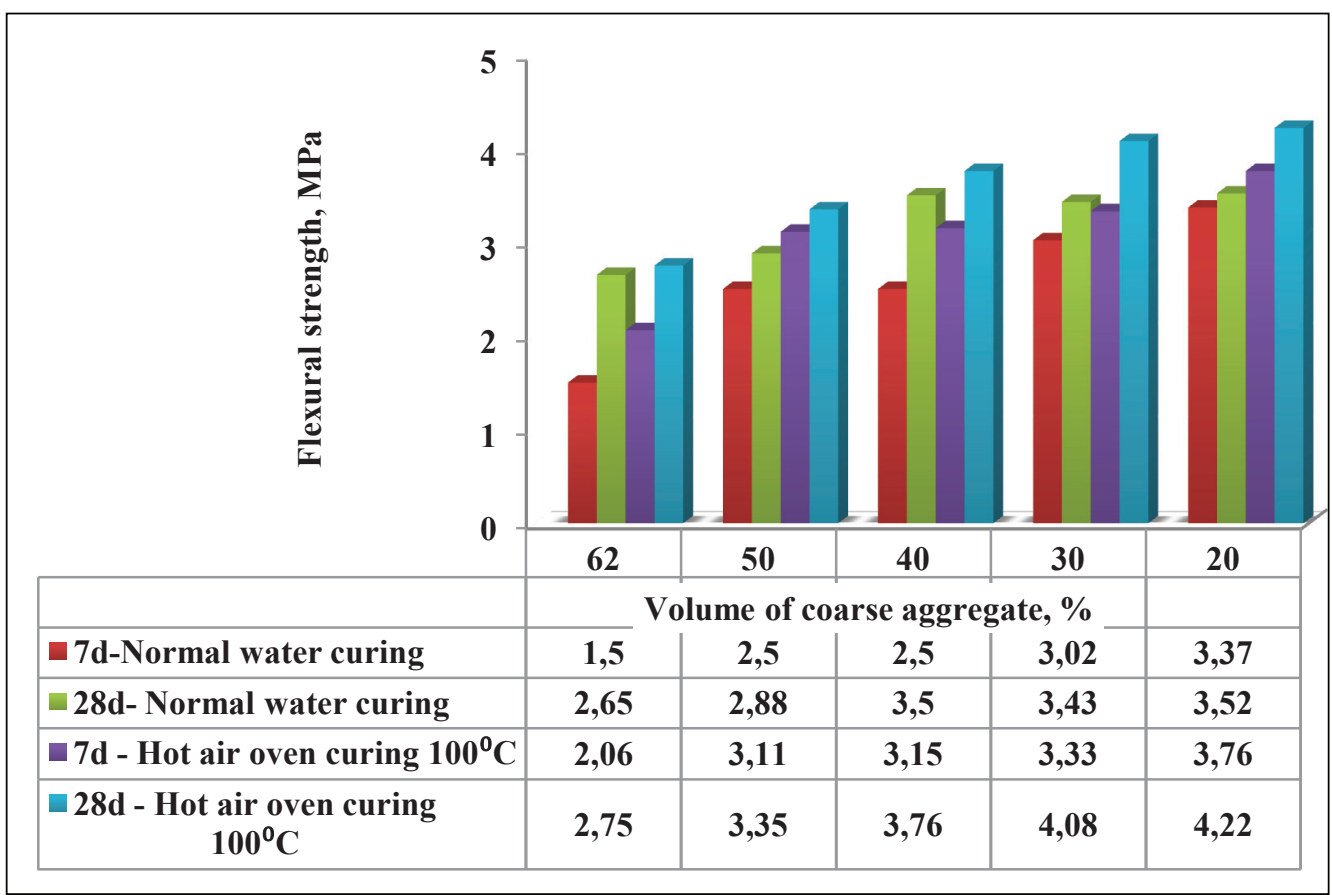

Fig. 20. Flexural strength of fly ash-bentonite aggregate concrete in water curing and hot air oven curing

\begin{tabular}{|ll}
\hline & \\
\hline
\end{tabular}

Fig. 21. Flexural strength of fly ash-metakaolin aggregate concrete in water curing and hot air oven curing 


\section{Conclusions}

The following important conclusions are drawn within the limitations of the present study:

- The chemical activation of fly ash was found to be an effective method for initiating the geo-polymerization reaction of fly ash with silicate minerals of benonite and metakaolin.

- Reaction of alkali with fly ash was much effective at higher curing temperature obtained in hot air oven at $100^{\circ} \mathrm{C}$.

- The pelletization efficiency was found to be higher when fly ash is mixed with binders i.e, GGBS which resulted in the uniform formation of round shape of fly ash balls at 15 minutes pelletization duration.

- In terms of water absorption, efficiency and crushing strength, fly ash aggregates containing GGBS (30S2-100) were found to exhibit better performance than fly ash bentonite aggregates.

- In the case of fly ash-GGBS aggregates the water absorption value was found to be lower (13.01\%) and a higher value of $21.26 \%$ was reported for alkali treated fly ash aggregates.

- Bulk density of metakaloin aggregates was found to be lower $\left(848.41 \mathrm{~kg} / \mathrm{m}^{3}\right)$ and highest density of $983.44 \mathrm{~kg} / \mathrm{m}^{3}$ was recored for fly ash-GGBS aggregates.

- A maximum crushing strength $(22.81 \mathrm{MPa})$ was obtained in the case of alkali activated fly ash-GGBS aggregates. In the case fly ash-metakaolin and fly ash-benonite a maximum crushing strength (17.62 $\mathrm{MPa}$ and $14.51 \mathrm{MPa}$ respectively) was obtained when the aggregates are cured in $100^{\circ} \mathrm{C}$ hot air oven.

- The impact strength of all three type of binders added in aggregates was less than $40 \%$ which is falling within the specified limits to be used as a construction material.

- Concrete proportions designed using maximum aggregate packing model showed a reduction in workability due to aggregate friction and were found to be improved with the increase in mortar phase. For bentonite, $40 \%$ pelletized aggregate and $60 \%$ mortar mix showed better workability.

- A highest compressive strength of $31.98 \mathrm{MPa}$ was recorded in the case of fly ashGGBS aggregate concrete (20S-CB) and $31.22 \mathrm{MPa}$ in the case of fly ash- bentonite aggregate concrete mixes (20BT-CB) at oven curing $100^{\circ} \mathrm{C}$. However, it was reported a strength loss in the case of maximum packing of aggregate due to lesser binder and plane of failure occurring through the aggregates.

- The maximum split tensile strength of $4.18 \mathrm{MPa}$ was obtained in the case of fly ash-GGBS aggregate concrete (20S-CB) as compared to fly ash aggregate (without binder) of $2.22 \mathrm{MPa}$ in hot air oven curing.

- The maximum flexural strength of fly ash-GGBS aggregate concrete subjected to hot air oven curing was found to be higher $(4.33 \mathrm{MPa})$ than the normal water curing (3.61 MPa) concrete mixes. 
- Strength properties were much improved in the case of oven cured concrete specimens due to faster chemical reaction required for complete hydration.

- The test results from this study clearly denote that the different types of fly ash based aggregates produced in this study satisfy the essential lightweight aggregate properties. In terms of strength, the addition of binder and alkali activator with fly ash provided adequate mechanical strength.

\section{REFERENCES}

1. K. I. Harikrishnan, K. Ramamurthy, Influence of Pelletization Process on the Properties of Fly Ash Aggregates, Waste Manag, 26, 846-852, 2006.

2. J.M. J.M. BIJEN, The manufacturing processes of artificial lightweight aggregates from fly ash, Int. J. Cement Composites Lightweight concrete, 8, 3, 191-9, 1986.

3. R. Manikandan, K. RamamuRthy, Influence of fineness of fly ash on the aggregate pelletization process, Cement Concrete Composites, 29, 456-464, 2007.

4. R. Manikandan, K. Ramamurthy, Effect of Curing Method on Characteristics of Cold Bonded Fly Ash Aggregate, Cement Concrete Composites, 30, 848-853, 2008.

5. K. Ramamurthy, K. I. Harikrishnan, Influence of binders on properties of sintered fly ash aggregate, Cement Concrete Composites, 28, 33-38, 2006.

6. Wang Lijiu, Zhang Shuzhong, Zhao Guofan, Investigation of the Mix Ratio Design of Lightweight Aggregate Concrete, Cement Concrete Res., 35, 931-935, 2005.

7. Bekir Ilker Topcu, Tayfun Uygunoglu, Properties of Autoclaved Lightweight Aggregate Concrete, Build. Environ, 42, 4108-4116, 2007.

8. C. L. Verma, S. K. Handa, S. K. Jain, R. K. Yadaw, Techno-commercial perspective study for sintered fly ash light-weight aggregates in India, Constr. Build. Mater, 12, 341-346, 1998.

9. S. Geetha, K. Ramamurthy, Properties of Sintered Low Calcium Bottom Ash Aggregate with Clay Binders, Constr. Build. Mater, 25, 2002-2013, 2011.

10. Niyazi Ugur Kockal, Turan Ozturan, Effects of lightweight fly ash aggregate properties on the behavior of lightweight concretes, Journal of Hazardous Materials, 179, 954-965, 2010. 